\title{
ORIGINAL PAPER \\ Child Welfare in the South Pacific: Deciding Child Protection Matters Across Pasifika Nations
}

\author{
Rosemary Sheehan ${ }^{1}$ (D)
}

Accepted: 1 August 2021/Published online: 11 August 2021

(C) The Author(s), under exclusive licence to Springer Nature Switzerland AG 2021

\begin{abstract}
The Asia-Pacific region is undergoing rapid change, and family structures and functioning are not exempt from this. Economic growth and urbanisation greatly affect the livelihood of family households across the Pacific Island countries. These changes take place against a backdrop of increasing inequity, rapid growth in technology, changes in traditional employment structures and a changing climate. Key social indicators suggest that violence, abuse and exploitation of children in the Pacific Island nations challenge their most vulnerable and marginalised children (Save the Children, 2019). To make the Pacific safe for every child, a number of nations are developing legal and regulatory frameworks for children's protection, with child and family welfare systems that address behaviour, attitudes and policies related to child protection concerns. This article examines key 'grey' literature drawn from UN, NGO and government documents, to offer an overview of what legal and welfare systems are in place in the Pacific Island nations in regard to child protection needs. It draws on Parton's (Parton, International Journal on Child Maltreatment 3:19-34, 2020, p. 20) suggestion that a range of political, cultural and sociological influences shape child protection policies which vary according to both time and place and family and community values. What the literature uncovers is the challenges Pacific Island nations face implementing such legal and regulatory frameworks for children's protection, what supports are needed to support any changes (UNICEF, 2015a, b), their need to address the United Nations Convention on the Rights of the Child, and to work with local communities, if there is to be effective reform around child wellbeing and safety, and their protection from harm (United Nations Convention on the Rights of the Child (UNCRC), 1989).
\end{abstract}

Keywords Child protection · Pacific Islands · Child welfare and the law $\cdot$ UNCRC

Rosemary Sheehan

sheehan@monash.edu

1 Department of Social Work, Monash University, Victoria, Australia 


\section{Introduction}

The Pacific Island region is made up of islands and island groups in Oceania which largely remained colonies or territories of foreign powers until after the World War II. Fiji, for example, in 1970, and the Solomon Islands in 1978 ended almost a century of British rule. For Kiribati it was not until 1970 and Tuvalu 1978 that they became independent nations. The island nations in many ways still hold to traditional indigenous ways of life and retain, across some islands, quite isolated communities, wary of outsiders challenging their community values.

South Pacific Island countries are profoundly affected by rapid change in key social and economic indicators, by growth in technology and changes to traditional employment structures and a backdrop of increasing inequity. Such changes sit alongside the major impacts of a changing climate and impact livelihood strategies of family households, deeply affecting family structures and functioning.

The conflicts and tensions of external world demands, social changes and community values are evident in how issues affecting children are managed. Violence, abuse and exploitation of children in the South Pacific Island nations are challenging their most vulnerable and marginalised children (Save the Children, 2019). Recognising such vulnerability, a number of Pacific nations are developing legal and regulatory frameworks to embed children's safety, introducing child and family welfare frameworks to address behaviour, attitudes and policies related to child protection concerns. To make the Pacific safe for every child, they recognise the need to address the key requirements of the United Nations Convention on the Rights of the Child, to protect the civil, political, economic, social and cultural rights of every child, regardless of race, religion or abilities (United Nations Convention on the Rights of the Child (UNCRC), 1989), recognising also that such child welfare systems integrate indigenous culture and beliefs into welfare models to affirm respect and equity for these groups. This article captures some of these key issues, within the breadth and complexity of the region, but is not an exhaustive critique of the many variables that shape policy and social change in the region.

Negligible research attention has been given to child safety across the Pacific Island nations. This article sets out to explore what literature there is on legal and regulatory frameworks for children's protection in the South Pacific Island countries; what literature there is is largely provided by 'grey literature' or publications disseminated by NGOs, international aid organisations, the UN and government reports, offering situational analyses of the specific challenges Pacific Island nations face in regard to child protection needs, what supports and resources are needed to implement changes (UNICEF, 2015a, b) and what are the drivers in ongoing development. This article draws on Parton's (2020, p. 20) proposition that a range of political, cultural and sociological influences shape child protection policies, which vary according to both time and place. He suggests that this is a perspective that is important for any future reforming of such policies.

Whilst there is a sense of shared regional identity in the Pacific Islands, their environments are diverse with traditional governance systems which respond to the particular character of each regional context. The Pacific Island nations have small 
populations and are vulnerable to the economic and climate challenges associated with contemporary rapid social changes in their region (Smith \& Jones, 2007). There is ongoing negotiation between national governments and local communities about customary land management, dealing with changes in population and the movement of people away from villages to larger towns for work, and the need to set in place structures that reflect contemporary responsibilities facing the Pacific states.

They struggle to establish effective health and education systems, to cope with urbanisation and loss of customary land and to set in place structures that provide stable government and life resources (work, power, water, housing etc.) The Lowy Institute (2018) highlights a number of key challenges for the Pacific Islands: demography, urbanisation, immigration, health and health systems, gender relations, and governance; and the Pacific Island nations' governments struggle to manage these. Population shifts from rural to urban living puts pressure on families' livelihoods and has increased tensions around the rights and roles of women and children, and their right to feel safe from harm. The balance between the child rights perspective articulated, for example, by UNCROC, may sit uneasily with traditions of cultural respect and power arrangements.

\section{Child Protection Defined}

Tilbury (2018, p. 181) reminds that what is acceptable treatment of children is defined according to a particular community's views and values and that what is accepted as child abuse and neglect will reflect that community's social norms about childhood and child rearing. As Parton (2020) suggests, what is accepted as child abuse will also reflect national political and economic frameworks, as will be the attention given to meeting children's needs through broader social policy on, for example, income support, health, housing and education. Tilbury (2018) underlines that the provision of child protection policy and responses turns both on securing an absence of child maltreatment and on the broader society being pro-active about 'crucial determinants of children's wellbeing' (Tilbury, 2018, p. 181) and recognising the key social drivers of policy that shape child wellbeing. Such a focus on wellbeing identifies the enduring impact that child maltreatment can have on a child throughout the course of their life (Save the Children, 2019; Sheehan, 2019). It acknowledges also what Parton (2020, p. 20) has noted that wellbeing encompasses the broader socio-cultural and political influences and community values, surrounding a child as much as specific events or actions that will affect an individual child's functioning.

UNICEF (2016, p. 23) confirmed that a child protection system requires a legal and policy framework compliant with the UN's Convention on the Rights of the Child (1989), international standards and good practices. These then need to be linked to a range of preventive, early intervention and responsive services, across social welfare, justice, health and education, for children and families. These elements are dependent on human and financial resources and on effective agency coordination (UNICEF, 2016, p. 24) Finally, there needs to be a capacity to gather 
data, to monitor and to evaluate the effectiveness of any child protection system (UNICEF, 2015a, b, p. 24).

Save the Children's Report Unseen and Unsafe (2019) describes a child protection crisis in the Pacific, with limited legislation and law enforcement in place to cope with the rising incidence of child abuse and domestic violence. UNICEF Pacific () flagged the urgent need to integrate children's protection into national development agendas, putting governments on notice as needing to be the key stakeholders in approaches to child wellbeing and safety. They urged the building of a human rights culture for children, and an attitudinal shift in what needs to be in place, to not only provide for the physical care of children but also a living context that promotes their growth and development (UNICEF, 2016, p. 23). Recognising how this has been addressed in other countries, and how this sits alongside providing for the physical care of children. Central to this, justice systems have to recognise when children are victims of undeserved adult actions and intervention in family life is needed, alongside strong intervention policies that allow for child protection (UNICEF, 2016, p. 24).

\section{Distinct Challenges in the Pacific}

Children in the Pacific face distinct factors that make them more vulnerable to exploitation and abuse. Save the Children's Report Unseen and Unsafe (2019) describes how the low status in general of children, weak institutional and governance systems and growing poverty and inequality all contribute systemically to high levels of child abuse. This is embedded in patriarchal societies with high levels of gender inequality, together with a disturbing social acceptance of physical punishment of children. Other factors that render these children more vulnerable to exploitation and abuse include violence and abuse in the family and community, social and economic marginalisation, a lack of livelihood opportunities (consistent education, opportunities for work, independent living and relationships, for example) for children and young people as well as community and societal attitudes, social norms and other structural factors (UNICEF, 2015a, b).

Rates of violence against children in Pacific Island Countries are among the highest in the world (UNICEF, 2019a, b, p. 1). In the Pacific islands, about four in every five children between 2 and 14 years experiences some form of violent discipline. Violence against children occurs not only at home and community levels, in schools and in religious institutions, but also where children are sent to work in industrial areas and on large projects (such as logging or mining sites). Szaier and Attenborough (2017) outlined why a large number of children live away from their parents. Adults with biological children living away from home range from $6 \%$ in Vanuatu to $25 \%$ in Kiribati and in the Solomons; in Fiji, the proportion is $11 \%$. The majority of these children are girls, who are at a higher risk of violence, abuse and exploitation. Parents do not always have means to check on the wellbeing of their child directly and trust that caregivers provide proper care and protection (Szaier \& Attenborough, 2017). But they are children, who as noted are generally at higher risk of abuse, and there are negligible protections of their rights or safety. 
The UNICEF (2008, p. 2) Child Protection Strategy turned its attention to the causes underpinning child vulnerability, looking to a child's immediate environment of family and community, to develop targeted interventions and work with parents to better understand the impact of their actions and thus to reduce violence and abuse against children. The UNICEF East Asia and Pacific Region Child Protection Programme Strategy $(2007$, p. 19) reminded how challenging this is given the factors that make children and families vulnerable are complex and inter-generational and grounded in community attitudes, practices and behaviours. UNICEF (2012, p. 24) found that a key barrier to reducing this vulnerability is the lack of comprehensive social protection systems that can reduce known social risks. In many of the Pacific nations, families and carers can struggle to care for their children, with limited access to essential services, such as healthcare and education, and entrenching inequality. Yet, UNICEF (2012, p. 17) emphasised how social protection measures can support families when faced with livelihood shocks, like unemployment, loss of a family member or a disaster. Such social protection measures are both economic and social, put in place to address poverty and deprivation, ensuring a child has the right to social security, to a standard of living 'adequate for their physical, mental, spiritual, moral and social development (to be) realised' (Article 27) (see United Nations Convention on the Rights of the Child (UNCRC), 1989). The measures countries 'take (to have) appropriate measures to assist parents and others responsible for the child to implement this right [to an adequate standard of living]' (see United Nations Convention on the Rights of the Child (UNCRC), 1989) will depend on their own economic and social stability, and this is challenged by the combination of external factors across the Pacific region already noted (UNICEF, 2012, p. 42).

\section{Impacts on Children}

Save the Children (2019) in their report Unseen and Unsafe on child vulnerability in the Pacific Islands reported on violence perpetrated against children, noting that between 70 and 87 per cent of children across eight countries in the Pacific experienced violence in the home, some suffering serious physical injuries and others experiencing unwanted pregnancy, sexually transmitted infections, mental trauma and even death (Save the Children, 2019, p. 2). The impact of such violence can have, as already noted, a lifelong impact on a child's physical, cognitive and social development, with a child carrying the legacy of the experience into adulthood and ongoing generations (Save the Children, 2019, p. 3).

Szaier and Attenborough's (2017) child protection baseline research in the Pacific examined this impact of child maltreatment. They referred not only to the immediate impacts on a child's individual health, and enduring effects on physical and mental health, but outcomes from this such as 'risky behaviours', where children who have experienced or witnessed abuse, exhibit behavioural problems, are vulnerable to substance abuse, in order to manage the trauma and stress they have experienced (Szamier \& Attenborough, 2017, p. 45). They described how women in Lae (PNG) spoke about the impact of family and sexual violence on their children; how their boys in particular turned to drugs, homebrew and alcohol; and unlawful activities, 
modelling the physical and verbal abuse of their abusing fathers (Szamier \& Attenborough, 2017, p. 56).

Mothers in the Solomon Islands described children who had been exposed to violence as having nightmares, being timid and withdrawn and, in some cases, running away (Szamier \& Attenborough, 2017, p. 59), as examples of the emotional and behavioural consequences of child abuse and cumulative harm.

UNICEF's Pacific Multi-Country Child Protection Program (2014-2018) emphasised that to protect children in the Pacific from violence, abuse, neglect and exploitation, governments needed to tackle the economic challenges faced by the Pacific communities, as these created the circumstances that enabled child abuse and violence against children. Their review of communities in Papua New Guinea, Solomon Islands and Vanuatu confirmed that to target the protection of children, governments had to deliver effective healthcare, education and child protection programs, as part of an overall strategy to reduce the human consequences of child maltreatment..

\section{Context and Challenges}

Poverty, inequality and unemployment are making it harder for families to meet the basic needs of their children for food, medical care, education, secure housing and family life. Traditional patterns of child rearing in many Pacific countries and the familial sharing of child caring duties and protection by kin (UNICEF, 2018, p. 21) are being challenged by rapid urbanisation, and by growing poverty, the family unit and kin network is losing its broader family protective mechanisms. Pressure on parents to earn cash has meant both men and women are often absent for long periods from their children, working as labourers in Australia or New Zealand, or on cruise ships, away for up to 6 months at a time. Children are left to the care of others, increasing their vulnerability to neglect and an increased risk of violence (p. 33), often propelling children into exploitative work (UNICEF, 2018, p. 33). A large number of children (about 22\%) live with or are informally 'adopted' by extended family within the kin system (UNICEF, 2018, p. 21), but this practice of informal adoption has, at times, led to exploitation of children in domestic labour, often neglected and exposed to sexual abuse (UNICEF, 2018, p. 23). Children in Pacific societies have low status and power and are largely voiceless with minimal rights; their parents are the key decision-makers (UNICEF, 2018, p. 24). The powerful cultural norms of obedience and family unity see children expected to contribute to the family economy (UNICEF, 2018, p. 25), thus limiting their life opportunities.

The combination of natural disasters and the impact of climate change diminish economies across the Pacific, reduce the availability of sufficient jobs for the number of job-seekers (AusAID, 2012, p. 4), and contribute to high rates of unemployment particularly among young people (UNESCAP, 2015, p 14). The consequent lack of opportunities for young people perpetuates a cycle of socio-economic vulnerability and risks of substance abuse, teenage pregnancy, crime and violence that accompany it (AusAID, 2012). These small island economies, their vulnerability to changes in the global economy and their isolation from global markets all affect family poverty in the Pacific (World Bank, 2015 p. 14). The migration of adults as 
workers away from home, as noted, to Australia, and New Zealand, intensifies these economic and social impacts, with households dependent on income sent back to support families (World Bank, 2015, p. 14).

\section{Norms, Attitudes and Practices}

Child labour in many of the Pacific Island countries is a concern, especially when children are doing potentially harmful work: street vending, scavenging or scrap metal collecting, portering and market services and housework. In rural areas, children are often working in hazardous agricultural work, such as carrying heavy crops, fishing, mining and logging. Girls, and boys, in these settings, isolated from family and protective relationships, are particularly vulnerable to sexual exploitation (UNICEF Pacific, 2017, p. 180). Few of the Pacific nations have given priority to child protection within the labour sector; few have initiatives to address child labour or legal frameworks for protection from child labour. However, the ILO is working with the Pacific countries to set a minimum age for children's work across all sectors and to prohibit children under the age of 18 from harmful or hazardous work (ILO, 2010, p. 12).

Child marriage rates are a concern in the Pacific, with one in every five girls marrying before the age of 18 . In the Solomon Islands, child marriage and the bride price may be seen as a solution to economic hardship (Save the Children, 2015, p. 45). The UN Human Rights Commission notes that child and forced marriage is an international concern, and the impact of COVID-19 has seen this increase in the face of economic impacts, isolation and less monitoring of girls at risk (OHCHR: child, early and forced marriage, including in humanitarian settings, 2021). Whilst there is a general minimum age of child marriage set at the internationally accepted age of 18 years, this minimum age of marriage can be reduced, to as low as 15 years in Tonga and Solomon Islands, if the permission of a parent/guardian is obtained. In some cases child marriage is allowed even without permission. In Fiji, the Convention of the Rights of the Child Committee raised concerns about the marriage of young girls in Indo-Fijian communities to overseas partners (UNFPA, p. 18). The fishing, mining and logging industries, for which foreign workers travel to the Pacific Islands, are known to target children for commercial sexual exploitation (Save the Children, 2015, p. 45). Children were also found to be exploited in child prostitution networks and brothels in bars and hotels (Fiji, Kiribati, RMI), on fishing or shipping vessels (FSM, Kiribati, Solomon Islands), and in the logging and mining industry (RMI, Solomon Islands) (Save the Children, 2019). The Economic and Social Commission for Asia and the Pacific (ESCAP, 2014, p. 20) found between 26 and 29 percent of children in Tonga and Tuvalu 2012, p. 23) lived below the basic needs poverty line; in Kiribati, 21.8 per cent of the population was living below the basic needs poverty line. Poverty rates were higher in rural locations, particularly on outlying islands (ESCAP, 2014, p. 20). In Fiji, 36.7 per cent of the rural population was described as living in poverty, compared to 19.8 per cent in urban areas (Pacific Community, 2013). The impact of such poverty is more significant for children (United Nations Development Programme, 2014, p. 96), yet government services 
and infrastructure and funding to meet the healthcare and education needs of these children is limited or non-existent. In the Solomon Islands, rural areas lack electricity and have inadequate access to basic services, including schools and health clinics, basic infrastructure and resources.

Violence is a normalised and widely condoned part of everyday life in many societies in the Pacific. Corporal punishment of children is socially accepted, and this normalisation of violence is a disincentive to women and children seeking help (UNICEF, 2019a, b, p. cy6). This acceptance of violence is a barrier to others getting involved in what is considered a private family affair. Gender inequality in deeply patriarchal communities sustains violence against women and children within these societies (UNICEF, 2019a, b, p.27).

Pacific children are exposed to high rates of family violence in their homes. Child Protection Baseline Studies undertaken in Fiji, Kiribati, Samoa, Solomon Islands and Vanuatu (UNICEF, 2015a, b), showed high prevalence rates of corporal punishment, with nearly half of ever-partnered women reported experiencing intimate partner violence: 23 percent of women in Kiribati, 11 per cent of women in Solomon Islands and 15 per cent in Fiji, reported being beaten during pregnancy (UNICEF, 2015a p. 4).

Sexual abuse against boys and girls in the Pacific is an issue of concern, and, in Samoa, the National Human Rights Institution (NHRI) noted in its submission to the Universal Periodic Review (UPR) (2015) that, despite sexual abuse and incest being prohibited and 'condemned' by both law and custom (fa'asamoa), they are in fact prevalent (Samoa's NHRI 2015, para. 23). In Vanuatu, the United Nations Human Rights Council reported that 'Vanuatu has one of the highest rates of incest amongst girls aged 15 years in the region' (UNHRC, Universal Periodic Review: Vanuatu, 2014, para. 23).

Trafficking of children in the Pacific Islands (US State Department p. 169) is a major concern, where children are forced into labour and girls into sexual prostitution. The culture of silence around issues of family and sexual violence contributes to children's vulnerability: in the Pacific there is a view that violence against children is a private 'family matter' which both perpetuates the violence and is a barrier to reporting and intervention (Save the Children, 2015, p. 12). The smaller Pacific nations make it difficult to report violence against children; their small size and familial connections create peer pressure and stigma against reporting such violence against children (UNICEF Pacific, 2017, p. 17). Shame, plus lack of access to services, further contributes to under-reporting (Save the Children, 2015, p. 64). A form of trafficking is seen in the informal 'adoption' of children in the Pacific Islands countries, both by foreign nationals and by national citizens. The practice of 'giving' one child to another family member (sometimes involving some form of remuneration for the child) has been noted in Pacific countries. The Solomon Islands practice of informally 'adopting' girl children to obtain unpaid workers is still common and creates conditions in which girls can be mentally, physically and sexually abused in their adopted homes (Save the Children, 2015). There is an urgent need for a review of such informal adoption practices to put in place controls and give preference to family-based kinship and foster care arrangements that are more childrights sensitive (UNICEF Pacific, 2017). 
The majority of child protection problems throughout the Pacific, even serious cases, are resolved within the family or through informal community interventions, rather than using formal child protection structures, particularly in rural areas and the outer islands (UNICEF Pacific, 2017). The concern with this is that a community's focus can be more on maintaining peace in the community rather than ensuring a protective environment for children (UNICEF Pacific, 2017).

\section{Child Protection Systems}

The Pacific Regional Framework, developed in 2006, and the UNICEF Child Protection Programme 2008-2012 set out to strengthen prevention and responses to child abuse by building up national systems (UNICEF, 2008). It was recognised that whilst governments were recognising child protection as a policy concern, they lacked resources, capacities and legal frameworks to address it. The 2008-2012 strategy outlined better protection for children by introducing legislation and by coordinating child protection social services that can respond to child abuse, but also encourage families and communities to create home and community environments that are protective for their children.

Whilst significant progress has been made in terms of ratifying the CRC obligations on child rights and protection, and efforts have been made to develop domestic legislation that meets these international obligations (UNICEF, 2019a, b), there is variable government priority given to child protection issues, with few resources given to preventative mechanisms or to effectively implement laws and policies that can protect children from harm. The type of resource-intensive welfare models, with professional staff delivering services that are characteristic of the developed world, are difficult to achieve in cash strapped Pacific countries, which lack the human and financial resources needed to deliver effective child and family welfare services. In Vanuatu, for example, whilst there is a stated national child protection policy, a lack of resources and understanding of what needs to be in place to make this workable, and the lack of a nuanced understanding of the particular needs and vulnerabilities of children in each country context, means there is reliance on relatives, family elders, chiefs and church pastors, as the first point of contact for both children and families who need support and dispute resolution (UNICEF, 2019a, b). There remains a fragmented approach to national child protection policies in most Pacific Island countries.

The Pacific Regional Workshop on Child Protection for the Social Welfare Sector (UNICEF, 2019a, b) brought together government representatives from 12 Pacific Island countries to develop a framework to improve child protection services in the region. UNICEF (2008) had, in partnership with Pacific governments, established evidence of high levels of violence against children at home and in schools, and a need for a multi-country child protection programme to strengthen their prevention of and response to child abuse.

UNICEF provides financial and technical support to develop child protection laws in the Pacific, and between 2014 and 2017, Fiji, Kiribati, Nauru, Samoa, Solomon Islands, Tuvalu and Vanuatu have put in place a broad architecture for a child 
protection system, and legislation, but on their own they are insufficient to deliver real change for children (Szamier \& Attenborough, 2017). There are few alternative care options for children at risk, who are mostly in kinship care, but this is problematic when they cannot be safely placed with a family member. Fiji and Samoa have residential care facilities, but how well they are supported and monitored is variable. What is yet to be added to any child protection programmes is a greater focus on good forms of child-rearing practices, as well as social supports and material resources, along with safeguards for children separated from their parents (Szamier \& Attenborough, 2017).

Some Pacific nations are seeking to strengthen the capacity of the legal system to handle child victim cases (UNICEF Pacific, 2017). Fiji has established a specialised child protection division, with guidelines for how legal and judicial officers approach child protection matters. Samoa established a specialist court in 2013 to deal with family violence and child protection cases. But the lack of specialised approaches remains a barrier for children's access to justice in child abuse matters (UNICEF Pacific, 2017).

The management of children in conflict with the law varies although there are specialist courts in the Cook Islands, Fiji, Kiribati, Samoa, Solomon Islands and Vanuatu (UNICEF Pacific, 2017). The Cook Islands has introduced Koro Akaau (The Enclosure of Resolving Matters), a restorative justice process within the Children's Court, modelled on the New Zealand Pasifica or Rangatahi Court. Samoa has recognised the importance of Samoan customs and processes in their approaches, using community-based sentences and out-sourcing mediation to communities, to the link informal justice and Samoan cultural practices (UNICEF Pacific, 2017). Offences involving children in conflict with the law and child victims are still largely resolved informally through community mechanisms. Whilst in some ways this restorative justice approach is positive for children, there are concerns about a lack of monitoring and oversight of these practices, which sometimes involve the use of corporal punishment (UNICEF Pacific, 2017). As noted earlier, they can also be seen to prioritise community peace and harmony over the best interests of the child. Although custodial sentences appear to be rarely used for children in conflict with the law in the Pacific, there are limited, if any, support services for child rehabilitation (UNICEF Pacific, 2017).

\section{System Challenges}

Whilst attention has been given to raising awareness in the Pacific about child protection issues through national campaigns and community participation, few of the Pacific nations have clear protocols and procedures for the reporting of child protection concerns, relying often on informal arrangements with health, police and NGO service providers (UNICEF, 2015a, b, p. 27).

There has been attention given however to improving parenting practices, to understanding children's rights and promoting violence-free discipline practices, and a focus on what are the roles and responsibilities of parents (UNICEF, 2015a, b). But support services are few for children in need of protection and their families, 
and while government agencies provide medical treatment etc., the social services that there are are primarily provided by NGOs and church groups (UNICEF, 2015a, b, p. 27).

Whilst Parton (2020, p. 20) argued that child protection policies are a confluence of political, cultural and sociological influences combined with family and community values, the fragmented approach to child protection in the Pacific does not reflect this straightforward confluence. Szaier and Attenborough (2017) describe how it is substantially left NGOs such as UNICEF to propose approaches and polices to respond to child protection concerns. Pacific nations vary greatly in their awareness of child protection concerns. There are no cross-national agreements on what a successful child protection programme should look like in the Pacific; and what is in place is a fragmented set of policies and recommendations by agencies working in the Pacific. There is negligible community consultation, or reference to contemporary political and social influences, to decide on 'what works' and how best to support and monitor progress.

Whilst UNICEF and other NGOs have provided guidance for the development of child welfare systems, the extent to which the Pacific Island nations can and do develop their systems varies greatly. Some of the bigger nations, such as Fiji, do now allocate funds for child protection, although the follow through can be problematic because of resource constraints, both human and financial. Others countries, such as the Solomon Islands and Vanuatu, are very dependent on UNICEF funding to introduce community child protection projects. Pacific community child protection projects are thus highly variable and inconsistent in terms of funding, staffing, commitment and ideas about desirable outcomes (Szamier \& Attenborough, 2017, p. 197). UNICEF has funded child protection officers, in some of the Pacific nations, but the officers have lacked an ongoing operational budget and the resources needed to travel to communities to implement supports. A lack of funding to introduce community child protection projects has frustrated attempts to develop specific supports for vulnerable families and children.

These inconsistencies reflect local difficulties in gathering support from local communities to develop community-initiated ways to protect children. The political and cultural influences Parton (2020) refers to that shape attitudes to children, and their need for protection, do not always sit easily with family and community values, which may be directly challenged by the changes they suggest, and so hinder the introduction of ideas about child safety and child protection.

There are examples of system change, however. Fiji's Ministry of Education has introduced a child protection policy, embedded in its education system, which requires all schools to appoint a child protection officer to oversee child protection concerns, stating there is a 'zero tolerance' approach to child maltreatment, violence and bullying (Szamier \& Attenborough, 2017, p. 109). Samoa, Nauru, the Cook Islands and Kiribati are focussing on child wellbeing in schools, and how children can protect themselves when vulnerable. But the broader public welfare systems are still limited in terms of policies that identify and respond to children at risk of harm. It would be expected that the health sector has a major role in responding to children's health safety needs, both in terms of prevention and responding to harm against children, as the health system is often the entry point for children 
who are abused. Yet child protection strategies are largely absent from few health sector policy or health service delivery. And, few if any attempts have been made to gather the support of the public health nurses and other health workers offering community outreach services to work collaboratively around child protection issues; certainly, they are given negligible training, if any, in child welfare matters (Szamier \& Attenborough, 2017, p. 157). The availability of a workforce that can combine professional and knowledge about intervention with community familiarity needs to underpin any new child protection agencies. So too how to bring together particular social work knowledge about child protection, for example, with the aims and resources of community development and international aid processes?

The possibility for and success of national child protection plans in the Pacific are vulnerable to external factors that can disrupt community functioning and constrain the finances and resources that governments can commit to health and welfare policy. A backdrop of changes in climate, and associated natural disasters, together with changes in traditions, are creating significant economic and social strain across all the 14 Pacific nations. The impacts of climate change are escalating, with flooding, tropical storms and cyclones, together with rising sea levels and extreme temperatures and becoming more frequent and intense, threatening a way of life that has sustained island communities for centuries. Such disasters damage crops and houses, often physically separating families, bringing poverty and hardship. This has a significant effect on the safety, education, health and future of children, making them vulnerable to child protection concerns, especially when they are moved away from their families and protective networks (Burton et al., 2011, p, 64). Schools can be destroyed, sometimes taking years to reopen; healthcare systems suffer; children are often more exposed to maltreatment when a community is fragmented after a disaster (Burton et al., 2011, p, 61).

The lack of national child protection plans intensifies these impacts. Children, their families and communities need in place strategies that help them prepare for and recover from disasters. Safe places such as schools have an important role in helping children manage the effects of natural disasters (UNICEF Pacific, 2017).

\section{Future Responses}

UNICEF Pacific (2008) in their Child protection in the Pacific from 2008-2014 emphasised the work needed to be done by governments, local partners and communities to develop robust child protection systems to ensure child safety. It is no solution to adopt models of child protection from Western nations whose social and institutional contexts vary significantly from those found in the Pacific region. What UNICEF's Child Protection Strategy (2008) confirmed is the importance of the Pacific Island nations developing their own ways to protect children, achieving this by working with local communities to change the social norms and values if children are to feel safe from harm.

The UNICEF Child Protection Strategy's (2008) regional overview of Fiji, Samoa, Vanuatu, Kiribati and the Solomon Islands further confirmed that any legislation and social services developed to ensure greater protection for children 
had to build on behaviour changes by families and communities and awareness of what contributes to child abuse and violence. Crispin et al. (2006) in their Pacific Regional Framework reported, however, that whilst governments are increasingly recognising child protection as a policy concern, they lack resources, capacities and legal frameworks to address it. They lack also coordinated child protection social services to provide effective responses to child protection concerns. Save the Children (2019) emphasises that healthcare and education are essential for a child focus as part of a broader systems response. This mirrors the socio-ecological framework adapted by WHO (2016) and the Centers for Disease Control and Prevention (CDC, 2021), to invest in a broad range of health, social and economic strategies, alongside institutional protection systems, to tackle child abuse but ensuring they are culturally appropriate solutions. The WHO (2016, p. 7) notes however that in promoting safe environments and justice for children in the Pacific, child protection strategies have to be practical, realistic community-initiated strategies for child protection.

Tackling the issue of child abuse and violence against children in the Pacific though must be more than a focus on solely developing intervention strategies. Save the Children (2019) remind that the structural drivers of child abuse must be addressed. It is getting right the balance between respecting traditions and transforming harmful norms and social practices that are culturally embedded, so that family and community take responsibility for child care and promote child wellbeing. New solutions are needed that build on the strengths and weaknesses of local custom, are collaborative and position policies developed with what are international obligations to realise the rights of children generally.

\section{Declarations}

Conflict of interest The author declares no competing interests.

\section{References}

Asian Development Bank. (2012). Pacific social protection series: Poverty, vulnerability and social protection: Kiribati case study. AusAid.

AusAID. (2012). Poverty, vulnerability and social protection in the Pacific: The role of social transfers. Commonwealth of Australia. See: https://www.dfat.gov.au/sites/default/files/social-transfer.pdf.

Burton, D., Mustelin, J. and Urich, P. (2011). Climate change impacts on children in the Pacific: A focus on Kiribati and Vanuatu. Advocacy Paper, commissioned by UNICEF Pacific in series: Climate Change and Children in the Pacific Islands. UNICEF.

Centers for Disease Control and Prevention. (2021). The social-ecological model: A framework for prevention. CDC.

Crispin, V., Thompstone, G., Tassone, C. \& Casey, S. (2006). National child protection systems in the East Asia and Pacific region: A review and analysis of mappings and assessments. Prepared for Child Frontiers Ltd. Hong Kong: ECPAT International. See: https:/www.who.int/publications/i/ item/inspire-seven-strategies-for-ending-violence-against-children.

ESCAP. (2014). United Nations Economic and Social Commission for Asia and the Pacific. State of human development in the Pacific. Suva: ESCAP Regional Office.

ILO. (2010). Child labour in Fiji: A survey of working children in commercial sexual exploitation, on the streets, in rural agricultural communities, in informal and squatter settlements and in schools. Report released 16 December 2010. ILO Country Office for South Pacific Island Countries. 
ILO. (2013). Youth employment brief: Pacific Island countries. See: http://www.youthmetro.org/uploa ds/4/7/6/5/47654969/youth_employment_policy_brief_pacific_islands_countries.pdf.

Pacific Community. (2013). The household income and expenditure survey for Fiji. Pacific Community.

Parton, N. (2020). Addressing the relatively autonomous relationship between child maltreatment and child protection policies and practices. International Journal on Child Maltreatment, 3, 19-34.

Samoa's National Human Rights Institution. (2015). Samoa's second universal periodic review. Submitted 21 September 2015. Ombudsman, Samoa.

Save the Children. (2014). National child protection systems in the East Asia and Pacific region. Child Frontiers Ltd and ECPAT International. https://www.savethechildren.org.au/media/media-releases/ evac-report-launch.

Save the Children. (2015). Dynamics of child trafficking and commercial sexual exploitation of children in Solomon islands. DFAT.

Save the Children. (2019). Unseen and unsafe: Underinvestment in ending violence against children in the Pacific and Timor-Leste. Report on joint research by Save the Children, Save the Children, Plan International and ChildFund. Save the Children.

Sheehan, R. (2019). Cumulative harm in child protection: The hidden concern. Australian Social Work, 72(4), 434-446.

Smith, A. \& Jones, K. L. (2007). Cultural landscapes of the Pacific Islands. UNESCO. World Heritage Committee. Paris: International Council of Monuments and Sites (ICOMOS).

Szamier, M. \& Attenborough, J. (2017). Review of UNICEF Pacific child protection programme. Final Report. DFAT. See: https://www.dfat.gov.au/sites/default/files/unicef-pacific-multi-country-childprotection-programme-independent-review.pdf.

Tilbury, C. (2018). Social work in child protection settings. In M. Alston, S. McCurdy \& J. McKinnon (2018). Social work fields of practice ( $3^{\text {rd }}$ ed.), pp. 180-195.

UNESCAP. (2015). Income support schemes in Pacific Island countries: A brief overview. ESCAP.

UN Human Rights Council. (2014). Universal periodic review: Vanuatu, compilation of UN information. UNHRC.

UN Human Rights Commission. (2021). Office of High Commissioner. Child, early and forced marriage, including in humanitarian settings. OHCHR. See: https://www.ohchr.org/en/issues/women/wrgs/ pages/childmarriage.aspx UN Human Rights Commission.

UNICEF. (2007). Child maltreatment: A systematic review of research. Bangkok: UNICEF East Asia and Pacific Regional Office (EAPRO). See: https://www.unicef.org/Child_Maltreatment.pdf.

UNICEF. (2008). Child protection strategy. Released 20 May 2008 by the UN Children's Fund, The United Nations Economic and Social Council. See: https://resourcecentre.savethechildren.net/node/ 12082/pdf/UNICEF\%20Child\%20Protection\%20Strategy_English.pdf.

UNICEF. (2012). Social protection strategic framework. Social and Economic Policy Analysis Unit.

UNICEF (2015a). Child protection systems governance. Four Pacific countries: Regional overview. UNICEF Pacific. See: https://www.unicef.org/pacificislands/what-we-do/child-protection

UNICEF (2015b) Harmful connections: Intersections of links between violence against women and violence against children in the South Pacific. UNICEF Pacific.

UNICEF. (2016). Child protection resource pack. See: https://data.unicef.org/resources/child-protectionresource-pack/.

UNICEF. (2018). UNICEF Pacific multi-country child protection program. See: https://www.dfat.gov.au/ sites/default/files/unicef-pacific-multi-country-child-protection-programme-independent-review.pdf.

UNICEF. (2019a). 12 Pacific Island communities commit to improve child protection services. Regional Workshop, 31 May 2019. https://www.unicef.org/pacificislands/press-releases/12-pacific-islandcountries-commit-improve-child-protection-services-regional.

UNICEF. (2019b). Violence against children in East Asia and the Pacific: A regional review and synthesis of findings. See: https://www.unicef.org/Violence_against_Children_East_Asia_and_Pacific.pdf.

UNICEF (ud). What we do in child protection. See: https://www.unicef.org/pacificislands/what-we-do/ child-protection.

UNICEF Pacific. (2017). Situation analysis of children in the Pacific Island countries. UNICEF Pacific.

United Nations Convention on the Rights of the Child (UNCRC) (1989). New York: Office of the High Commissioner, Human Rights, United Nation https://www.unicef.org.uk/what-we-do/un-conve ntion-child-rights/.

United Nations Development Programme (2014). The state of human development in the Pacific. Suva: UNDP. See: https://www.unescap.org/sites/default/files/The\%20State\%20of\%20Human $\% 20$ Dev elopment\%20in\%20the\%20Pacific\%28LORes\%29.pdf. 
United Nations Population Fund. (2008). An assessment of the state of violence against women in Fiji. UNFPA.

US State Department. (2016). Trafficking in persons report. June 2016. See: https://2009-2017.state. gov/j/tip/rls/tiprpt/2016/index.htm.

WHO. (2016). INSPIRE: Seven strategies for ending violence against children. WHO.

World Bank. (2015). Hardship and vulnerability in Pacific Island countries. World Bank Group.

Publisher's Note Springer Nature remains neutral with regard to jurisdictional claims in published maps and institutional affiliations. 